\title{
Perbandingan Kerapatan Kolagen Ligamentum Sakrouterina pada Pasien dengan dan tanpa Prolaps Uteri
}

\author{
Intan Renata Silitonga, ${ }^{2}$ M. Rizkar A. Sukarsa, ${ }^{1}$ Lasma R. Pohan, ${ }^{3}$ Edwin Armawan, ${ }^{1}$ Budi Handono ${ }^{1}$ \\ ${ }^{1}$ Rumah Sakit Rajawali Bandung, ${ }^{2}$ Departemen Obstetri dan Ginekologi Fakultas Kedokteran Universitas \\ Padjadjaran/Rumah Sakit Dr. Hasan Sadikin Bandung, ${ }^{3}$ Departemen Patologi Anatomi Fakultas Kedokteran \\ Universitas Padjadjaran/Rumah Sakit Dr. Hasan Sadikin Bandung
}

\begin{abstract}
Abstrak
Kerapatan kolagen merupakan satu faktor penting dalam kejadian prolaps uteri. Beberapa penelitian menunjukkan pasien prolaps uteri mempunyai kerapatan kolagen ligamentum sakrouterina yang rendah. Penelitian ini bertujuan mengukur perbedaan kerapatan kolagen ligamentum sakrouterina pada pasien dengan dan tanpa prolaps uteri. Penelitian ini adalah penelitian analitik komparatif dengan case control study terhadap 16 pasien prolaps uteri dan 16 pasien tanpa prolaps uteri di Rumah Sakit Dr. Hasan Sadikin Bandung dan RS jejaring periode November-Desember 2008. Bahan penelitian diambil dari ligamentum sakrouterina saat operasi histerektomi lalu dibuat sediaan dengan pewarnaan hematoksilin-eosin dan Masson's trichrome. Uji kemaknaan menggunakan uji Mann-Whitney. Hasil penelitian didapatkan hubungan bermakna antara kerapatan kolagen dan kejadian prolaps uteri, yaitu kerapatan kolagen pada pasien prolaps uteri lebih rendah $(15,3 \%)$ dibanding dengan tanpa prolaps uteri (48,75\%). Cut-off point kerapatan kolagen ligamentum sakrouterina untuk prediksi prolaps uteri adalah S 30\%; sensitivitas 93,8\%; spesifisitas 87,5\%; dan akurasi 90,6\%. Simpulan penelitian ini adalah bahwa kerapatan kolagen ligamentum sakrouterina pada pasien prolaps uteri lebih rendah dibanding dengan pasien tanpa prolaps uteri. Cut-off point kerapatan kolagen ligamentum sakrouterina yang dapat memprediksi prolaps uteri adalah $\leq$ 30\%. [MKB. 2015;47(4):212-7]
\end{abstract}

Kata kunci: Kerapatan kolagen, ligamentum sakrouterina, prolaps uteri

\section{The Comparison of Uterosacral Ligament Collagen Density in Patients with and without Uterine Prolapse}

\begin{abstract}
Collagen density is one important factor in uterine prolapse. Several studies has shown that uterine prolapse patients have lower uterosacral ligament collagen density. The purpose of this study was to reveal the uterosacral ligament collagen density differences in patients with and without uterine prolapse. This case control study was an analitic comparative research of 16 uterine prolapse patients and 16 patients without uterine prolapse who underwent hysterectomy in Dr. Hasan Sadikin General Hospital Bandung and its networking hospitals during November-December 2008. Uterosacral ligament was sampled and then stained using HE and Masson's trichrome staining. The significance of the result was analyzed using Mann-Whitney. The study found a significant correlation between collagen density and uterine prolapse, with the collagen density of uterine prolapse patients was lower $(15.3 \%)$ than patients without uterine prolapse $(48.75 \%)$. The uterosacral ligament collagen density cut-off point in predicting women having uterine prolapse was $\leq 30 \%$; with $93.8 \%$ sensitivity, $87.5 \%$ specificity, and $90.6 \%$ accuracy. The conclusion of this study is that uterosacral ligament collagen density in patients with uterine prolapse is lower $(15.3 \%)$ than patients without uterine prolapse $(48.75 \%)$. The uterosacral ligament collagen density cut-off point in predicting a women having uterine prolapse is $\leq 30 \%$. [MKB. 2015;47(4):212-7]
\end{abstract}

Key words: Collagen density, terine prolapse, uterosacral ligament

Korespondensi: Intan Renata Silitonga, dr., SpOG., M.Kes, Rumah Sakit Rajawali Bandung, Jalan Rajawali Barat No. 38 Bandung Jawa Barat 40184, mobile 08122030179, e-mail intan_renata@yahoo.co.id 


\section{Pendahuluan}

Prolaps uteri merupakan kondisi penurunan uterus ke dalam vagina (prolaps inkomplet) ataupun keluar dari vagina (prolaps komplet) akibat melemahnya jaringan ikat penyokong uterus. ${ }^{1,2}$ Prolaps uteri merupakan penyakit yang banyak terdapat di masyarakat dan kejadiannya meningkat seiring paritas dan usia. Insidensi prolaps uteri belum diketahui secara pasti. Pada sebuah penelitian di Amerika Serikat tahun 2004 terhadap 16.000 pasien didapatkan 14,2\% menderita prolaps uteri. Terdapat penelitian lainnya di Amerika Serikat tahun 2004 dan diungkapkan bahwa estimasi $11 \%$ dari seluruh wanita memiliki risiko akan menjalani operasi prolaps organ pelvis. ${ }^{3,4}$ Di Amerika Serikat, usia yang dihubungkan dengan kejadian operasi prolaps uteri adalah wanita usia di atas 50 tahun, yaitu $2,7-3,3$ prolaps uteri per 1.000 wanita. ${ }^{3}$ Pada penelitian di Inggris tahun 2001, insidensi tahunan operasi prolaps uteri adalah 2 per 1.000 orang. ${ }^{3} \mathrm{Hal}$ ini memperlihatkan angka operasi yang tinggi dibanding dengan prosedur operasi yang lain yang dilakukan pada wanita. Keadaan ini merupakan fenomena gunung es karena angka tersebut hanya memperlihatkan wanita yang menjalani operasi prolaps uteri. Angka tersebut tidak termasuk wanita dengan prolaps uteri yang tidak menjalani operasi, wanita yang dirawat bukan karena prolaps uteri, dan wanita yang tidak pernah berobat. Kurang lebih 200.000 operasi prolaps uteri dilakukan di Amerika Serikat setiap tahunnya. ${ }^{3,4}$

Gregory dkk. ${ }^{5}$ menyatakan bahwa insidensi prolaps uteri bervariasi pada ras tertentu. Ras Kaukasia dan Spanyol mempunyai risiko tinggi perkembangan prolaps uteri dibanding dengan ras Asia, Afrika, dan India. Kejadian prolaps uteri di Indonesia belum banyak ditemukan datanya. Menurut laporan tahunan Departemen Obstetri dan Ginekologi Rumah Sakit Dr. Hasan Sadikin (RSHS) tahun 2006, dari 1.455 kasus ginekologi yang dirawat, terdapat 30 kasus prolaps uteri dan dari 30 kasus tersebut terdapat 13 kasus prolaps uteri yang dilakukan histerektomi vaginal. ${ }^{6}$

Beberapa faktor terpenting dalam kejadian prolaps uteri yaitu faktor usia, hormon estrogen, kerapatan kolagen, cedera melahirkan, obesitas, batuk kronik, dan konstipasi kronik. ${ }^{1,3}$ Di antara faktor penting tersebut, yang akan diteliti pada penelitian ini adalah kerapatan kolagen. Faktorfaktor penting lainnya yang perlu diperhatikan pada kejadian prolaps uteri adalah faktor usia, indeks massa tubuh, dan cedera melahirkan sehingga diperlukan homogenitas sampel dalam penelitian ini. Di Amerika Serikat, usia yang dihubungkan dengan kejadian operasi prolaps uteri adalah wanita usia di atas 50 tahun. ${ }^{3}$ Pada penelitian Women's Health Initiative, wanita dengan obesitas, yaitu wanita dengan indeks massa tubuh di atas $30 \mathrm{~kg} / \mathrm{m}^{2}$ memiliki kejadian prolaps uteri yaitu dengan odds ratio 1,4-1,75 dibanding dengan wanita berat badan normal, yaitu indeks massa tubuh di bawah $25 \mathrm{~kg} / \mathrm{m}^{2,3}$ Faktor cedera melahirkan berhubungan dengan persalinan per vaginam dan beberapa penelitian menyatakan bahwa risiko terjadinya prolaps uteri akan meningkat bila wanita tersebut telah melahirkan tiga anak atau lebih. ${ }^{3}$

Kolagen merupakan salah satu struktur penting pada kekuatan dan elastisitas jaringan ikat dasar pelvis. Kolagen merupakan salah satu faktor penting dalam kejadian prolaps uteri. ${ }^{2}$ Kolagen mempunyai serat berbentuk S. Ketika kurva tersebut menjadi lurus akibat distensi, kolagen bekerja sebagai tali kaku sehingga dapat mencegah distensi lebih lanjut. Pada titik ini, kekuatan apapun yang diberikan akan langsung ditransmisikan. Karena itu, kemampuan distensi jaringan bergantung terhadap konfigurasi serat kolagen. $^{2}$

Hubungan antara kerapatan kolagen dan kejadian prolaps uteri serta perbandingannya dengan pasien tanpa prolaps uteri belum banyak ditemukan datanya. Beberapa peneliti berasumsi bahwa bila terjadi penurunan kerapatan kolagen maka dapat terjadi kelemahan pada jaringan ikat dasar pelvis dan kemudian dapat terjadi prolaps uteri. ${ }^{2}$ Beberapa penelitian pada perbandingan kerapatan kolagen ligamentum sakrouterina pada pasien dengan dan tanpa prolaps uteri menunjukkan pasien prolaps uteri mempunyai kerapatan kolagen ligamentum sakrouterina yang lebih rendah bila dibanding dengan pasien tanpa prolaps uteri. ${ }^{2}$

Penelitian kerapatan kolagen pada pasien prolaps uteri tersebut dilaksanakan di Eropa, Amerika, Inggris, Turki, Jerman, Brazil, dan juga Skandinavia, sementara penelitian di Indonesia mengenai hubungan antara kerapatan kolagen ligamentum sakrouterina dan kejadian prolaps uteri belum pernah dilakukan. ${ }^{2}$

Tujuan utama penelitian mengenai kerapatan kolagen ini yaitu mengetahui perbandingan kerapatan kolagen pada pasien dengan dan tanpa prolaps uteri serta menemukan metode pengobatan terbaru untuk mencegah kejadian prolaps uteri dari segi pengelolaan kerapatan kolagen pasien. 


\section{Metode}

Penelitian ini adalah analitik komparatif dengan rancangan case control study. Subjek penelitian adalah pasien prolaps uteri dan tanpa prolaps uteri yang datang ke Rumah Sakit Dr. Hasan Sadikin (RSHS) Bandung, RSUD Sumedang, RSUD Ujungberung, dan RSUD Garut selama periode November-Desember 2008.

Pengambilan sampel penelitian ini dilakukan secara konsekutif berdasarkan urutan datangnya pasien yang memenuhi kriteria inklusi dan tidak termasuk eksklusi serta besar sampel minimal. Kriteria inklusi meliputi kelompok pasien prolaps uteri stadium II, III, dan IVyang dilakukan operasi dan kelompok kontrol, yaitu pasien kista ovarium yang dilaksanakan histerektomi total, pasien mioma uteri yang dilakukan histerektomi total, pasien kanker serviks stadium IA-IIA yang dilakukan operasi histerektomi radikal dengan ligamentum sakrouterina yang tidak rusak, pasien kanker ovarium yang dilakukan operasi staging laparotomy dengan ligamentum sakrouterina yang tidak rusak. Seluruh pasien memiliki indeks massa tubuh normal (IMT: 18,5$24,9 \mathrm{~kg} / \mathrm{m}^{2}$ ), pasien dengan riwayat persalinan per vaginam sebanyak 3 kali atau lebih, dan pasien bangsa Indonesia.

Kriteria eksklusi ini meliputi pasien yang mempunyai penyakit penyerta lainnya (batuk kronik dan konstipasi kronik). Besar sampel dihitung menggunakan rumus untuk menguji dua rata-rata. Uji statistik yang digunakan adalah uji-t apabila sebaran data berdistribusi normal atau uji Mann-Whitney bila sebaran data tidak berdistribusi normal. Untuk mengetahui nilai ambang batas (cut-off point) kerapatan yang dapat dipakai sebagai prediksi terjadinya prolaps uteri dipergunakan perhitungan menggunakan kurva receiver operating characteristics (ROC). Selanjutnya, untuk mengendalikan variabel perancu dilakukan analisis stratifikasi. Analisis data dilakukan menggunakan program SPSS for windows versi 13.0. Kemaknaan hasil uji ditentukan berdasarkan nilai $\mathrm{p} \leq 0,05$.

\section{Hasil}

Penelitian kerapatan kolagen dilakukan terhadap 16 pasien prolaps uteri dan 16 pasien tanpa prolaps uteri sebagai kontrol. Dari penelitian ini didapatkan bahwa karakteristik usia pada kedua kelompok secara statistik bermakna $(p<0,05)$, usia $\geq 50$ tahun mempunyai risiko prolaps uteri sebesar 9 kali bila dibandingkan dengan usia < 50 tahun.

Demikian pula paritas, semakin tinggi paritas $\geq 5$ risiko prolaps uteri sebesar 10 kali bila dibanding dengan paritas 3 . IMT $18,5-22,9 \mathrm{~kg} /$ $\mathrm{m}^{2}$ mempunyai risiko prolaps uteri sebesar 3,67 kali bila dibanding dengan IMT $23-24,9 \mathrm{~kg} / \mathrm{m}^{2}$.

Dari gambaran karakteristik kedua kelompok yang bermakna ini maka dalam analisis berikut akan diperhitungkan sebagai variabel perancu.

Berdasarkan pada Tabel 1 terlihat median kerapatan kolagen pada penderita prolaps uteri lebih rendah dibanding dengan kelompok tanpa kejadian prolaps uteri, yaitu $10 \%$ berbanding $50 \%$. Hasil analisis berdasarkan atas uji MannWhitney memperlihatkan perbedaan kerapatan kolagen secara bermakna yaitu antara subjek penelitian yang mengalami prolaps uteri dan tanpa prolaps uteri $(\mathrm{p}<0,001)$. Beberapa contoh hasil pewarnaan hematoksilin eosin (HE) dan Masson's trichrome (MT) dapat dilihat pada Gambar 1, 2, 3, dan 4.

Selanjutnya, untuk mengetahui nilai ambang batas (cut-offpoint) kerapatan kolagen yang dapat dipakai sebagai alat prediksi kejadian prolaps uteri dilakukan perhitungan mempergunakan kurva receiver operating characteristics (ROC), hasilnya terlihat pada Gambar 5 .

Berdasarkan kurva ROC diperoleh cut-off point kerapatan kolagen yang dapat memprediksi kejadian prolaps uteri adalah $\leq 30 \%$; dengan besarnya sensitivitas $93,8 \%$; spesifisitas $87,5 \%$; dan akurasi 90,6\%.

Pada penelitian ini didapatkan hubungan yang sangat bermakna antara kerapatan kolagen dan kejadian prolaps uteri berdasarkan strata usia, yaitu pada usia $<50$ tahun terdapat 6 pasien

Tabel Hasil Pemeriksaan Kerapatan Kolagen Rata-rata pada Pasien Prolaps Uteri

\begin{tabular}{lcccc}
\hline \multicolumn{1}{c}{ Kerapatan Kolagen } & Prolaps Uteri (\%) & Tanpa Prolaps Uteri (\%) & $\mathbf{Z}_{\mathrm{M}-\mathrm{w}}$ & Nilai p \\
\hline Rata-rata (SB) & $15,31(11,47)$ & $48,75(14,08)$ & & \\
Median & 10 & 50 & 4,433 & $<0,001$ \\
Min-Maks & $5-40$ & $20-70$ & & \\
\hline
\end{tabular}

Keterangan: $\mathrm{Z}_{\mathrm{M}-\mathrm{W}}=$ Uji Mann-Whitney 


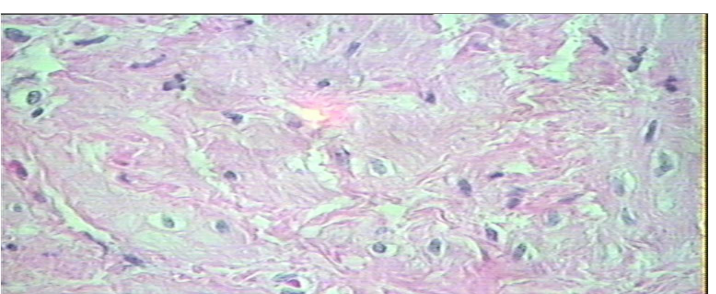

Gambar 1 Pewarnaan HE, Usia 55 Tahun, Paritas 5, Ca Cervix, Kerapatan 50\%

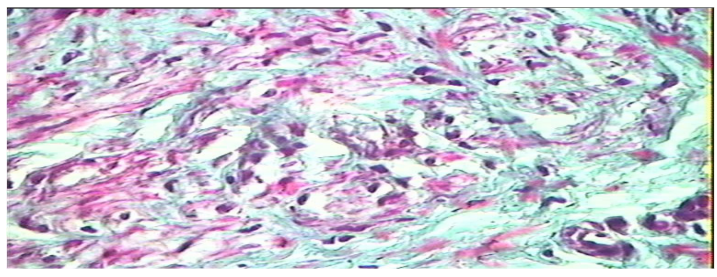

Gambar 3 Pewarnaan MT, Usia 44 Tahun, Paritas 8, Prolaps Uteri, Kerapatan $5 \%$

tanpa prolaps uteri dengan kerapatan kolagen $>30 \%$ dan pada usia 50 tahun terdapat 14 pasien prolaps uteri dengan kerapatan kolagen $£ 30 \%$. $^{3}$

Pada penelitian ini didapatkan hubungan yang sangat bermakna antara kerapatan kolagen dan kejadian prolaps uteri berdasarkan strata paritas adalah sebagai berikut: pada paritas 3 terdapat 7 pasien dengan prolaps uteri memiliki

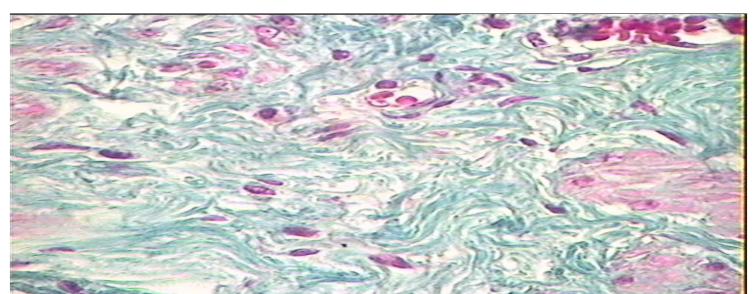

Gambar 2 Pewarnaan MT, Usia 55 Tahun, Paritas 5, Ca Cervix, Kerapatan 50\%

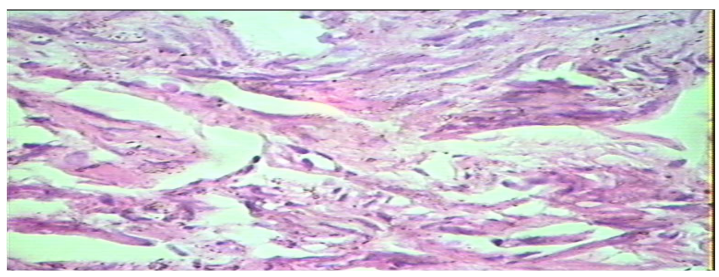

Gambar 4 Pewarnaan HE, Usia 82 Tahun, Paritas 3, Prolaps Uteri, Kerapatan $5 \%$

kerapatan kolagen $>30 \%$ dan pada paritas di atas 5 terdapat 11 pasien prolaps uteri dengan kerapatan kolagen $£ 30 \%$.

Pada penelitian ini didapatkan hubungan yang sangat bermakna antara kerapatan kolagen dan kejadian prolaps uteri berdasarkan strata IMT, yaitu tampak bahwa IMT $<23$ terdapat 10 pasien dengan prolaps uteri yang mempunyai

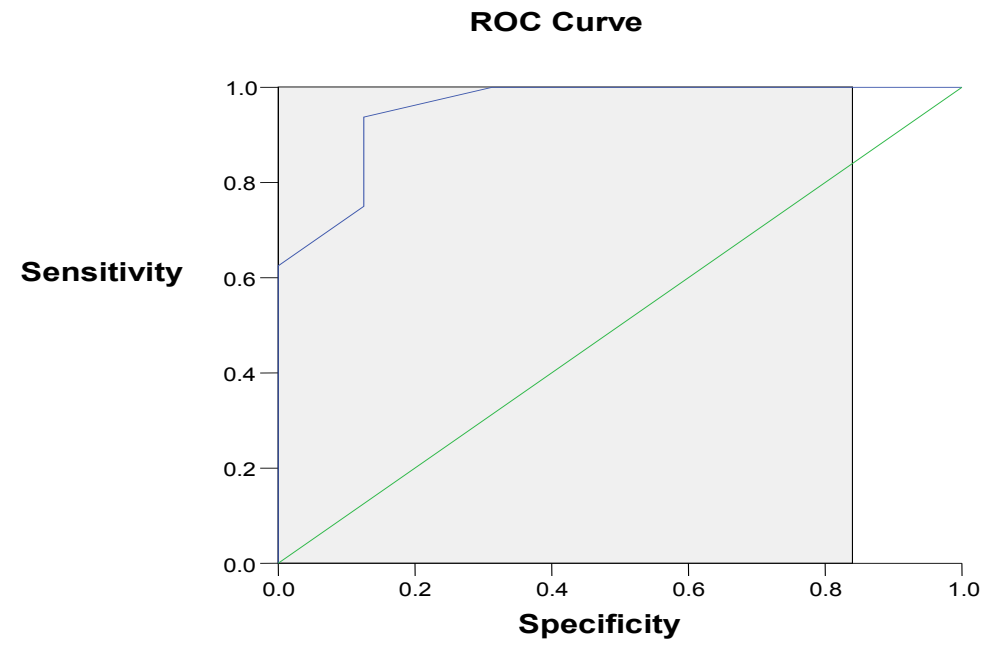

Gambar 5 Kurva ROC: Hubungan antara Spesifisitas dan Sensitivitas Kerapatan Kolagen dalam Memprediksi Prolaps Uteri 
kerapatan kolagen $£ 30 \%$ sementara pada IMT ${ }^{3}$ 23 terdapat 8 pasien tanpa prolaps uteri dengan kerapatan kolagen $>30 \%$.

\section{Pembahasan}

Pada penelitian ini karakteristik usia pada kedua kelompok secara statistik berbeda bermakna $(p<0,05)$, usia $\geq 50$ tahun memiliki risiko terjadi prolaps uteri sebesar 9 kali apabila dibanding dengan usia $<50$ tahun. Hal ini sesuai dengan pendapat Sandra, ${ }^{1}$ Petros, ${ }^{2}$ dan Weber $^{3}$ bahwa pada wanita usia muda, kolagen mudah untuk berekstensi sementara pada wanita usia tua akan terjadi suatu peningkatan penyilangan antarmolekuler dan juga intramolekuler kolagen sehingga kolagen tidak akan berekstensi dan jaringan ikat akan mengecil sehingga dengan usia meningkat maka kejadian prolaps uteri akan makin meningkat. Hasil penelitian ini juga sesuai dengan penelitian Weber $^{3}$ bahwa di Amerika Serikat usia yang dihubungkan dengan kejadian operasi prolaps uteri adalah wanita usia di atas 50 tahun. Karakteristik paritas pada kedua kelompok secara statistik bermakna $(\mathrm{p}<0,05)$, yaitu ditemukan bahwa semakin tinggi paritas (paritas $\geq 5$ ) maka risiko prolaps uteri sebesar 10 kali bila dibanding dengan paritas 3 . Hal ini sesuai dengan penelitian Tan dkk., ${ }^{7}$ Weber dan Waltres, ${ }^{8}$ dan Hendrix dkk. ${ }^{9}$ yang menyatakan bahwa cedera saat melahirkan terutama bila wanita tersebut mempunyai banyak anak atau mempunyai riwayat melahirkan bayi besar (lebih dari 9 pon). Dikatakan pula oleh Tan dkk., ${ }^{7}$ Weber dan Waltres, ${ }^{8}$ dan Hendrix dkk. ${ }^{9}$ bahwa cedera saat melahirkan pervaginam akan meningkatkan risiko prolaps uteri bila wanita tersebut telah melahirkan tiga anak atau lebih. Keadaan ini diakibatkan proses pematangan dan dilatasi serviks pada saat melahirkan terjadi melalui aktivasi beberapa kolagen dan elastase sehingga dapat mengurangi matriks jaringan ikat serviks. IMT $18,5-22,9 \mathrm{~kg} / \mathrm{m}^{2}$ mempunyai risiko prolaps uteri sebesar 3,67 kali bila dibanding dengan IMT $23-24,9 \mathrm{~kg} / \mathrm{m}^{2}$. Pada penelitian ini subjek penelitian merupakan pasien dengan indeks massa tubuh normal serta dibandingkan antara IMT $18,5-22,9 \mathrm{~kg} / \mathrm{m}^{2}$ dan IMT $23-24,9$ $\mathrm{kg} / \mathrm{m}^{2}$ yang merupakan klasifikasi normal rendah dan normal tinggi. Perbandingan antara indeks massa tubuh normal rendah dan normal tinggi pada pasien prolaps uteri ini tidak pernah dilakukan oleh penelitian sebelumnya. Penelitian yang sudah ada dilakukan oleh Women's Health Initiative, wanita dengan obesitas yaitu wanita dengan indeks massa tubuh di atas $30 \mathrm{~kg} / \mathrm{m}^{2}$ mempunyai kejadian prolaps uteri dengan odd ratio 1,4-1,75 dibanding dengan wanita berat badan normal, yaitu indeks massa tubuh di bawah $25 \mathrm{~kg} / \mathrm{m}^{2}$.

Berdasarkan Tabel tampak bahwa kerapatan kolagen rata-rata pada pasien prolaps uteri lebih rendah bila dibanding dengan kerapatan kolagen rata-rata pada pasien tanpa prolaps uteri, yaitu $15,3 \pm 11,47 \%$ berbanding $48,75 \pm 14,08 \%$. Median kerapatan kolagen pada penderita prolaps uteri lebih rendah bila dibanding dengan kelompok tanpa prolaps uteri, yaitu $10 \%$ berbanding $50 \%$. Hasil analisis berdasarkan atas uji MannWhitney memperlihatkan perbedaan kerapatan kolagen bermakna antara subjek penelitian yang mengalami prolaps uteri dan tanpa prolaps uteri $(p<0,001)$. Keadaan ini sesuai dengan penelitian yang dilakukan oleh Wong dkk., ${ }^{10}$ yaitu wanita dengan prolaps uteri mempunyai total kolagen $30 \%$ lebih rendah bila dibanding dengan kontrol. Penelitian lainnya yang menunjukkan hasil yang serupa adalah penelitian yang dilakukan oleh Wong dkk., ${ }^{11}$ yaitu kerapatan kolagen pasien prolaps uteri lebih rendah apabila dibanding dengan kadar kolagen pasien kontrol, yaitu 8,10\% $\pm 3,43 \%$ berbanding $12,35 \% \pm 4,72 \%(p=0,0104)$. Hasil penelitian ini sesuai dengan penelitian Barbiero dkk. ${ }^{12}$ yaitu pada pemeriksaan kualitas serat kolagen didapatkan kolagen pasien tanpa prolaps uteri lebih panjang dan lebih rapat dan kolagen pada pasien prolaps uteri lebih pendek, tipis, dan memiliki jarak yang lebih lebar antara serat. Pada penelitian ini dapat dilihat pada Gambar 1, 2, 3, dan 4. Penelitian ini serasi dengan penelitian Kokcu dkk., ${ }^{13}$ yaitu terjadi penurunan selularitas jaringan prolaps uteri bila dibanding dengan kontrol. Hasil penelitian ini juga serupa dengan hasil penelitian dilakukan oleh Takano dkk., ${ }^{14}$ yaitu jumlah kolagen pada parametrium wanita dengan prolaps uteri yang lebih rendah apabila dibanding dengan parametrium wanita tanpa prolaps uteri.

Berdasarkan kurva ROC diperoleh cut-off point kerapatan kolagen yang dapat memprediksi kejadian prolaps uteri adalah $\leq 30 \%$ dengan besarnya sensitivitas $93,8 \%$; spesifisitas $87,5 \%$; dan akurasi 90,6\%. Untuk penelitian cut-off point kerapatan kolagen yang mampu memprediksi kejadian prolaps uteri yang belum pernah ada penelitian sebelumnya sehingga hasil penelitian ini juga dapat menjadi acuan bahwa kerapatan kolagen $\leq 30 \%$ cenderung terjadi kejadian prolaps uteri yang lebih tinggi dibanding dengan kerapatan kolagen $>30 \%$.

Berdasarkan atas analisis stratifikasi usia 
didapatkan hubungan yang sangat bermakna antara kerapatan kolagen dan kejadian prolaps uteri berdasarkan atas strata usia. Penelitian sebelumnya menerangkan mengenai terdapat hubungan kerapatan kolagen dengan suatu kejadian prolaps uteri berdasarkan strata usia pernah dilakukan oleh Wong dkk. ${ }^{11}$ dengan hasil usia tidak menunjukkan hubungan dengan kerapatan kolagen.

Berdasarkan analisis stratifikasi paritas itu didapatkan bahwa pada paritas 3 dan paritas $\geq 5$ terdapat hubungan antara kerapatan kolagen dan kejadian prolaps uteri bermakna secara statistik. Penelitian sebelumnya yaitu mengenai hubungan kerapatan kolagen dengan kejadian prolaps uteri berdasarkan strata paritas pernah dilakukan sebelumnya oleh Wong dkk. ${ }^{11}$ dan didapatkan hasil bahwa paritas tidak dapat memperlihatkan ada hubungan dengan kerapatan kolagen.

Berdasarkan analisis stratifikasi IMT terdapat hubungan sangat bermakna antara kerapatan kolagen dan juga kejadian prolaps uteri $(\mathrm{p}<0,05)$ baik pada IMT $<23 \mathrm{~kg} / \mathrm{m}^{2}$ maupun IMT $\geq 23 \mathrm{~kg} /$ $\mathrm{m}^{2}$. Penelitian sebelumnya mengenai hubungan kerapatan kolagen dengan kejadian prolaps uteri berdasarkan strata IMT pernah dilakukan oleh Wong dkk. ${ }^{11}$ dan didapatkan hasil bahwa IMT tidak menunjukkan hubungan dengan kerapatan kolagen.

Simpulan, kerapatan kolagen ligamentum sakrouterina pada pasien prolaps uteri lebih rendah dibanding dengan pasien tanpa prolaps uteri. Cut-off point kerapatan kolagen ligamentum sakrouterina yang dapat memprediksi prolaps uteri adalah $\leq 30 \%$.

\section{Daftar Pustaka}

1. Sandra RV. Anterior compartment prolapse, urinary incontinence, and the effects of anterior colporraphy and paravaginal repair. Dalam: Gretchen ML, penyunting. Urogynecology. USA: Oxford University Press Inc; 2000. hlm. 118-31.

2. Petros $\mathrm{P}$, penyunting. The anatomy and dynamics of pelvic floor function and dysfunction. Edisi ke-2. Germany: Springer; 2004 ..

3. Weber AM. An overview of pelvic organ prolapse. Dalam: Weber AM, Brubaker L, Schaffer J, Toglia MR, penyunting. Office urogynecology. New York: McGraw-Hill; 2004. hlm. 189-96.

4. Walters MD, Weber AM. Anterior vaginal prolapse with and without genuine stress incontinence. Dalam: Cardozo L, Staskin D, penyunting. Textbook of female urology and urogynaecology. London: Martin Dunitz Ltd; 2001. hlm. 587-96.

5. Gregory SJ, Ganka N, Eric V, Shlomo R, Larissa VR. Familial tranmission of genitovaginal prolapse. Int Urogynecol J. 2005;16(17): 498-501.

6. RS. Dr. Hasan Sadikin Bandung; Universitas Padjadjaran, Bagian Obstetri dan Ginekologi. Laporan tahunan obstetri dan ginekologi RSHS, 2006. Bandung (Indonesia): Universitas Padjadjaran; 2006.

7. Tan JS, Lukacz ES, Menefee SA. Predictive value of prolapse symptoms: a large database study. Int Urogynecol J Pelvic Floor Dysfunct. 2005;16(3):203-9.

8. Weber AM, Walters MD, Piedmonte MR. Sexual function and vaginal anatomy in women before and after surgery for pelvic organ prolapse and urinary incontinence. Am J Obstet Gynecol. 2000;182(6):1610-5.

9. Hendrix SL, Clark A, Nygaard I. Pelvic organ prolapse in the Women's Health Initiative: gravity and gravidity. Am J Obstet Gynecol. 2002;186(6):1160-6.

10. Söderberg MW, Falconer C, Byström B, Malmström A, Ekman G. Young women with genital prolapse have a low collagen concentration. Acta Obstet Gynecol Scand. 2004;83(12):1193-8.

11. Wong M, Harmanli O, Agar M, Dandolu V, Grody MH. Collagen content of nonsupport tissue in pelvic organ prolapse and stress urinary incontinence. Am J Obstet Gynecol. 2003;189:1597-600.

12. Barbiero EC, Sartori MG, Girao MJ, Baracat EC, de Lima GR. Analysis of type I collagen in the parametrium of women with and without uterine prolapse, according to hormonal status. Int Urogynecol J Pelvic Floor Dysfunct. 2003;14(5):331-4.

13. Kokcu A, Yanik F, Cetinkaya M, Alper T, Kandemir B, Malatyalioglu E. Histopathological evaluation of the connective tissue of the vaginal fascia and the uterine ligaments in women with and without pelvic relaxation. Arch Gynecol Obstet. 2002;266(2):75-8.

14. Takano CC, Girao MJ, Satori MG, Castro RA, Arruda RM, Simoes MJ, dkk. Analysis of collagen in parametrium and vaginal apex of women with and without uterine prolapse. Int Urogynecol J Pelvic Floor Dysfunct. 2002; 13(6):342-5. 